\title{
Defining initial strength in clusterless languages in Strict CV
}

\author{
Nancy C. Kula and Lutz Marten
}

\section{Introduction}

Strength is defined by position in Strict CV so that the strength associated to the initial position and the weakness associated to 'codas' is a result of their position with respect to empty positions in a configuration of strictly alternating $\mathrm{C}$ and $\mathrm{V}$ positions. ${ }^{1}$ Within this configuration, government and licensing relations determine which positions are regarded as strong or weak. With respect to strength in initial position this must interact with a postulated initial (melodically empty) CV unit (Lowenstamm 1999) that marks the beginning of a word and that facilitates the categorisation of languages into those with only sonority-increasing clusters and those with either sonority-increasing or decreasing clusters in initial position. ${ }^{2}$ While these findings provide profound insight into how grammar characterises languages into two types with respect to the initial cluster type attested and makes predictions on the expected strength in initial position in these languages, it remains to be seen whether languages without clusters can draw on the mechanisms developed to define strength in initial position. This paper investigates whether this expanded theory sheds light on strength in initial position in languages without clusters, here dubbed clusterless languages. It will be shown that, contrary to what is seen in languages with clusters where the absence of the initial CV unit implies a weak initial position, clusterless languages provide evidence that although the initial $\mathrm{CV}$ unit is absent, the initial position still exhibits properties of strength. This lack of predicted weakness will be accounted for by parameterising proper government and suggesting that this governing relation has no role to play in clusterless languages. In the absence of proper government, an

\footnotetext{
${ }^{1}$ Strict CV is an emerging version of Government Phonology (Kaye, Lowenstamm and Vergnaud 1985, 1990) and is not to be confused with CV Phonology (Clements and Keyser 1983) or Radical CV Phonology (van der Hulst 1995).

${ }^{2}$ For ease of reference we will use simply 'initial CV unit' to refer to the 'melodically empty initial CV unit' for the remainder of this paper.
} 
alternative account of intervocalic weakening will also emerge from the discussion, in this way differentiating intervocalic from coda weakening. The paper develops as follows; $\$ 2$ discusses how positional strength is defined in Strict CV; $\$ 3$ discusses the distribution of the initial CV unit according to initial cluster type and the predictions that follow from this; $\S 4$ and $\$ 5$ aim to characterise strength in initial position in clusterless languages in two ways - firstly by investigating whether the initial CV unit has a role to play in these languages $(\$ 4)$ and secondly by looking at empirical evidence of weakening and strengthening processes in clusterless languages of the Niger-Congo phylum ( $\$ 5)$; $\$ 6$ maps out an enhanced picture of positional strength in Strict $\mathrm{CV}$ and $\$ 7$ offers some concluding remarks.

\section{Positional strength in Strict CV}

Strict CV, owing to Lowenstamm (1996), is an offshoot of Government Phonology (Kaye, Lowenstamm and Vergnaud 1985, 1990), also referred to simply as CVCV theory, which argues that phonological representations at the skeletal level consist of strictly alternating $\mathrm{C}$ and $\mathrm{V}$ positions. This implies that representationally there are no branching onsets or nuclei. The effect of surface consonant clusters is thus achieved by differing government and licensing configurations. In this sense languages differ not with respect to whether they allow branching structure or not but according to the government and licensing relations that they are able to sanction. Government and licensing, apart from sanctioning different syllable structure types, are the two main forces driving strength relations, defined specifically as in (1) based on formulations in Szigetavári (1999) and Scheer (2004).

(1) Government: inhibits the segmental expression of its target

Licensing: enhances the segmental expression of its target

In this sense then government is seen as a detrimental force to the expression of a segment, or more neutrally, to melody (i.e. the elements of which segments are composed). A position that is governed is less able to sanction the expression of material. Thus a $\mathrm{C}$ or $\mathrm{V}$ position that is governed diminishes its potential to license melodic material. Licensing on the other hand has a positive effect of sanctioning the expression of melody in the licensed position. An interesting and important change that has taken place 
in the transition from standard Government Phonology to Strict CV is that all (realised) nuclei in a domain or phonological word must license and govern. In contrast, in standard Government Phonology (SGP henceforth) all contentful nuclei license a preceding onset and also a preceding nucleus in order to propagate licensing potential through a phonological domain. The one outstanding unlicensed nucleus is deemed the head of the domain. Government on the other hand is a special type of licensing that is reserved for relations defining branching constituents (constituent government) or non-branching ones (inter-constituent government) or that holds between nuclei (proper government) used to define the occurrence of empty nuclei within a configuration. With the goal of simplifying the theory and placing no restrictions on nuclei, which even in SGP are able to both govern and license, nuclei in Strict CV are treated as being endowed with licensing and governing potential which they always aim to dispense. Thus a realised $\mathrm{V}$ position will always license and govern preceding material defining a phonological domain by a series of lateral relations (see Scheer 2004). Consider the illustration in (2) that compares a phonological domain in SGP and in Strict CV.

(2) Government and licensing relations in phonological domains ${ }^{3}$
a. SGP
$\mathrm{C}_{1} \stackrel{\nabla}{\mathrm{V}_{1} \mathrm{C}_{2}} \overrightarrow{\mathrm{V}}_{2} \mathrm{C}_{3} \mathrm{~V}_{3}$ licensing
b. Strict CV
$\cup \circlearrowleft$ licensing
$\square$
$\mathrm{C}_{1} \mathrm{~V}_{1} \mathrm{C}_{2} \mathrm{~V}_{2} \mathrm{C}_{3} \mathrm{~V}_{3}$

In SGP $V_{3}$ is the head of the domain (a role which is decided on language specific grounds) and the main source of licensing potential for the whole domain. By this token, $V_{3}$ licenses $V_{2}$ which in turn licenses $V_{1}$ making these nuclei able to license the $\mathrm{C}$ position that precedes them. No government is involved. In Strict CV, on the other hand, each V position both licenses and governs the preceding $\mathrm{C}$ position. The idea that licensing potential is distributed from a head nucleus to the other nuclei in the domain, as seen in the SGP illustration in (2a), is lost. The main motivation for this is to keep licensing relations local and lateral. For SGP to retain licensing

\footnotetext{
${ }^{3}$ We use C and V for both SGP and Strict CV just for ease of comparison here. SGP notationally uses $\mathrm{O}$ and $\mathrm{N}$ for Onset and Nucleus, which dominate timing slots of a skeletal tier. In Strict CV the sequence of C's and V's defines both the constituents and the timing tier.
} 
in (2a) it is generally assumed that the inter-nuclear relations involve hierarchical relations occurring at a higher nuclear level.

A positive effect of the Strict CV configuration in (2b) is that strength by position can be defined via the four logical interactions between government and licensing as illustrated in (3). ${ }^{4}$

$$
\begin{aligned}
& \text { A position } x \text { may be: }:^{5} \\
& \text { governed licensed strength status } \\
& \text { a. } \quad-\text { (good) }+ \text { (good) strong } \\
& \text { b. }+ \text { (bad) }+ \text { (good) weak } \\
& \text { c. } \quad-\text { (good) - (bad) weak } \\
& \text { d. }+ \text { - n not an option }
\end{aligned}
$$

We see in (3a) that if a position is not governed but is licensed it is strong because by being ungoverned its ability for segmental expression is not inhibited and in addition by being licensed its ability for segmental expression is enhanced. It will thus be a good position for segments to be expressed, reflected in no reduction in the amount of contrasts that can be expressed in such a position. If, as in (3b) on the other hand, a position is licensed, and therefore good for segmental expression, but is also governed, a consequence of which implies inhibition in the ability to sanction segmental expression, there will be a struggle between two opposing forces resulting in a reduction in the number of contrasts that may be expressed in such a position in comparison to one that is not governed but licensed.

\footnotetext{
${ }^{4}$ While it follows that a 'coda' can be characterised as weak in SGP because it is unlicensed by virtue of being followed by an empty nucleus, no difference in licensing is expressed between an initial and an intervocalic position, which are equally licensed but only the latter is (more widely) subject to weakening effects. We return to this issue in $\S 3$.

${ }^{5}$ The tags good and bad here are to be understood in relation to the realisation of melody. A position that is not governed is good because it escapes an influence that inhibits the expression of melody. A position that is governed is bad because it is subjected to an influence that inhibits melodic expression. A position that is licensed is good because it is subject to an influence that enhances melodic expression. And a position that is not licensed is bad because it fails to be subjected to an influence that enhances melodic expression. A position that is not licensed but is governed cannot exist because the absence of licensing indicates that the licensor (the adjacent vowel) is empty, in which case it also cannot act as a governor. The configuration in (3) follows from that fact that licensing relations are always local while government relations (such as proper government) may be non-local.
} 
Unlicensed positions are in general bad for segmental expression because such positions are not sanctioned to enhance melodic expression. Unlicensed and ungoverned positions as in (3c) will retain some ability to express information because though they are not licensed they are also not governed and are therefore not inhibited in the expression of segmental material. This is another case of opposing forces resulting in a reduction of the expression of contrasts, but as the position is not licensed it lacks positive influence and will therefore be weak. Positions that are unlicensed but governed are not an option because they present a contradiction in terms; if a position is unlicensed it is because it lacks a licensor, meaning that it is followed by an empty position. Since only realised filled positions are licit licensors and governors, a position cannot be unlicensed but governed - if it lacks a licensor then it also lacks a governor.

The strength abilities of positions can therefore be seen as part of a continuum from the strongest position where the two forces of government and licensing reinforce each other with positive effect, through an intermediate position where they oppose each other, ending with the weakest position where the two forces reinforce each other with a negative effect. Between the latter two options (3b) and (3c), where government and licensing oppose each other, $(3 b)$ is considered stronger than (3c) by virtue of having a positive setting for licensing. Positionally (3a) characterises the initial or post-coda position, ( $3 b)$ the intervocalic position and (3c) the coda.

Cross-linguistically it has been overwhelmingly observed that codas and intervocalic positions are usual targets of weakening processes. Ségéral and Scheer (2001: 24) give the following list of weakening processes and the positions they are most readily attested in.

$\begin{array}{ll}\text { in coda } & \text { in } V \_V \\ \text { typical } & \text { improbable } \\ \text { typical } & \text { improbable } \\ \text { typical } & \text { improbable } \\ \text { typical } & \text { improbable } \\ \text { typical } & \text { improbable } \\ \text { typical } & \text { improbable } \\ \text { typical } & \text { improbable } \\ \text { typical } & \text { improbable } \\ \text { typical } & \text { improbable } \\ \text { improbable } & \text { typical } \\ \text { improbable } & \text { typical }\end{array}$


From this set we see the imbalance between the coda and the intervocalic position with the former attesting more weakening processes than the intervocalic position from this sample set, argued to follow from the lack of licensing in coda positions.

By making reference to governing and licensing relations as discussed above, Strict $\mathrm{CV}$ is able to capture these observations. Note that the use of 'coda' is only notational in Strict CV since only a sequence of strictly alternating $\mathrm{C}$ and $\mathrm{V}$ positions is allowed and no level of the syllable (as in SGP) is adhered to. A 'coda' is therefore strictly defined as a C position followed by an empty $\mathrm{V}$ position, as seen in the representation of English cat in (5).

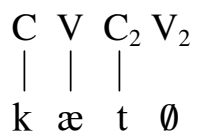

As already pointed out earlier in the discussion of the impossibility of having an unlicensed and ungoverned position, only realised vowels are licit governors and licensers. Thus in (5) $\mathrm{C}_{2}$ hosting the word-final /t/ cannot be licensed (or governed) by the empty final position $\mathrm{V}_{2}$ and is therefore subject to weakening effects as defined by the configuration in (3). Wordinternal codas in words like English contain for example are subject to the same treatment as word final codas in Strict CV since they are similarly followed by an empty $\mathrm{V}$ position. Intervocalic weakening, as seen in spirantisation processes in Spanish, for example, is treated as following from the weakening expected of a position that is governed despite being licensed. Note that by this token the initial position should also be weak since it is licensed but governed. This will be the main concern of $\S 3$.

Let us complete the picture by considering cases involving consonant clusters which are all represented as separated by an intervening empty nucleus. Does this entail that the initial $\mathrm{C}$ in every cluster is predicted to be weak? Obviously this is not desired. To understand how this is avoided we must elaborate on the nature of consonant cluster relations. Under specific conditions, certain consonant clusters, particularly ones of increasing sonority, are able to have a relation that renders the intervening $\mathrm{V}$ position between them inert. ${ }^{6}$ This follows from the more general distribution of cluster types across languages, an issue we will discuss for the initial posi-

\footnotetext{
${ }^{6}$ Kula (2002) refers to this state as an inability to project, which entails the inability to participate in any relations in the representation.
} 
tion in $\S 3$. In SGP such structures are presented in a branching structure and in addition have a governing relation that indicates the strict ordering of the members of the cluster. Scheer (2004 and elsewhere) argues at length that having both branching structure and governing relations is a duplication of tasks which have essentially the same goal - a restriction in the ordering relation of the cluster (see also Takahashi 2004). Strict CV therefore simplifies the representation by only having a governing relation holding between the members of the cluster termed infra-segmental government (Scheer 1996). Infra-segmental government (IG) is an asymmetric relation that holds between two positions where the governor is more complex than the governed position. ${ }^{7}$ When this relationship holds between two $\mathrm{C}$ positions, the intervening $\mathrm{V}$ position is licensed to be empty. Essentially it is treated as not being part of the configuration by virtue of being sandwiched in a relation between the two flagging $\mathrm{C}$ positions, and as such, it is not regarded as a potential governor of the initial $\mathrm{C}$ in a $\mathrm{CC}$ cluster. Instead, the $\mathrm{V}$ position following the cluster indirectly acts as the licensor of both $\mathrm{C}$ positions in the cluster by licensing $C_{2}$ to govern $C_{1}$ by virtue of which $C_{1}$ is licensed. This is the manifestation of government licensing in Strict CV from SGP (see Charette 1991 for details). Consider the illustration of this in English true in (6), where IG stands for infra-segmental government.

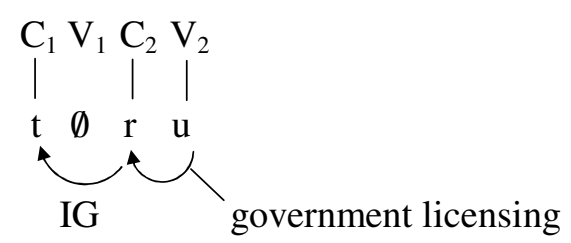

Thus as shown in the governing and licensing relations in (6), $C_{1}$ and $C_{2}$ contract a relation that renders $\mathrm{V}_{1}$ inactive thereby allowing $\mathrm{V}_{2}$ to license

7 Scheer (2004: 64) defines infra-segmental government specifically as involving government of an empty position within the melodic make up of a segment:

a. A consonant A may contract a governing relation with its neighbour B iff there is a place-defining autosegmental line where A possesses a prime, while the corresponding slot in the internal structure of B is empty. In this situation, the prime belonging to A governs the empty position of $\mathrm{B}$.

b. The empty nucleus enclosed within such a domain of infra-segmental government is circumscribed. Its Empty Category Principle is satisfied.

Note that this presents a type of government that still retains the basic idea of government, namely, the inhibition of segmental/melodic expression. 
$\mathrm{C}_{2}$ for its own expression and also to allow it to govern $\mathrm{C}_{2}$, in this way also indirectly licensing $\mathrm{C}_{1}$. By this token the initial position is not weak because it is licensed. However, if we allow for the fact that all nuclei play the dual role of governing and licensing in Strict $\mathrm{CV}$ then $\mathrm{V}_{2}$ still has governing potential that it needs to expend. If $\mathrm{C}_{1}$ or $\mathrm{C}_{2}$ are governed by $\mathrm{V}_{2}$ then we predict that whichever is governed will be weak with a reduction in the contrasts that can be expressed. This is untrue for $C_{1}$ based on crosslinguistic observation that the initial position is strong, so having $\mathrm{C}_{1}$ governed is an undesirable outcome. $\mathrm{C}_{2}$ on the other hand does display restrictions on the number of contrasts expressed in it but we know already that this is due to the infra-segmental governing relation that holds between $\mathrm{C}_{1}$ and $\mathrm{C}_{2}$, particularly in sonority-increasing clusters. The reduction in contrast expressed in $\mathrm{C}_{2}$ can therefore not be due to it being governed by $\mathrm{V}_{2}$. In $\S 3$ we discuss where the governing potential of $V_{2}$ goes to.

With regard to positional strength in Strict CV we have seen that by reference to government and licensing and how these two relations interact within a domain we can characterise the fact that codas, both final and internal, are weak because they always consist of a $\mathrm{C}$ position followed by an empty $\mathrm{V}$ position that is unable to license them. Intervocalic positions are weak or can show a tendency to be weak because they are both governed and licensed. So far, we have not seen how the word-initial position is differentiated from an intervocalic $\mathrm{C}$ position which is also followed by a realised vowel that can act as its licensor and governor and therefore make it also subject to some weakening effects. We turn to the resolution of this issue presently, after a word on how empty positions are regulated in Strict CV.

As we have seen from the representation of codas and clusters in Strict $\mathrm{CV}$, a plethora of empty positions is postulated by the theory and it would be good to lay out how these are regulated, when they are permissible, and what characteristics they have. Every empty position in a representation must be licensed via the Empty Category Principle in (7), which differs only minimally from that proposed in SGP (Kaye 1990).

(7) Empty Category Principle (ECP)

A nucleus may remain phonetically unexpressed iff it is;

a. properly governed

b. enclosed within a domain of infra-segmental government or

c. domain-final 
(7b) is the case we have just seen with the cluster in (6), while (7c) is a parametric option that some languages employ. Those languages that allow words to end in a consonant have the setting for this parameter on and those that have the parameter off always require words to end in a realised vowel. Proper government in (7a) is a way of sanctioning empty positions by ensuring that they are licensed via government by a following realised vowel. This implies that every empty position sanctioned by proper government must be followed by a vowel that acts as its licensor. A realised vowel may only properly govern one vocalic position and so cannot sanction a sequence of empty positions. Thus all empty positions must be licensed in one of the three ways above to ensure that they are structurally licit. However, their potential for licensing and government is entirely lost - they can neither license nor govern.

Let us now consider how the strength associated with initial position is accounted for in Strict CV.

\section{The initial CV unit and its predictions}

Lowenstamm (1999), in accounting for the distribution of word-initial clitics in Tiberian Hebrew, among other Semitic languages, proposes the idea that the beginning of a word is marked by an initial CV unit, qualifying this as applying only to words of major lexical categories. This, for example, explains why lexical words are able to act as hosts to clitics which themselves lack structure. The main motivation for the initial CV unit is that it allows reference to the left edge of the word, which, as Ségéral and Scheer point out, has been the basis of many disjunctive rules in phonology since SPE. The environments $\left\{\#, \mathrm{C}_{-}\right\}$have been used to define phonological rules contrasted from the final position or the coda $\{\ldots \#, \ldots$ C $\}$. The use of the initial CV unit turns what is otherwise a phonological diacritic into a phonological object that not only uniquely identifies the initial position but may also help explain some distributional patterns. Like all other empty structure in Strict CV, the initial CV unit must be licensed by proper government as defined in the ECP in (7). Under this understanding the initial $\mathrm{CV}$ unit can only be present in cases where there is available a following realised vowel that can act as its licensor via proper government. Once the initial CV unit is licit in a representation we expect that it plays a role in various phonological alternations. Let us review three arguments that support the existence of an initial CV unit. 
Lowenstamm (1996) analyses alternations between long vowels and gemination in the prefixation of the singular definite article $h a$-in Tiberian Hebrew with recourse to the initial CV unit. As the data in $(8 \mathrm{a}-\mathrm{c})$ show, the prefix $h a$ - causes the initial consonant of a noun to geminate, unless that consonant is a guttural. In the case of gutturals, there is no gemination but instead a lengthening of the prefix vowel, as seen in (8d).

(8) Tiberian Hebrew singular definite article alternations
a. $\sqrt{ }$ dgl degel 'flag'
ha-ddegel 'the flag'
b. $\sqrt{ }$ klb keleb 'dog'
ha-kkeleb 'the dog'
c. $\sqrt{ }$ nir naiar 'young man'
ha-nnaiar 'the young man'
d. $\sqrt{\text { Srb }}$ Sereb 'evening'
ha:-Sereb 'the evening'
(*ha- (Tereb)

The distribution in (8) follows neatly under an analysis that assumes the initial CV unit, which can be licensed in this case by the initial vowel of the noun. Being licensed in the structure, it can be the target of gemination in (9a) or of vowel lengthening in (9b), just in case the initial consonant of the noun is unable to geminate. ${ }^{8}$

(9)

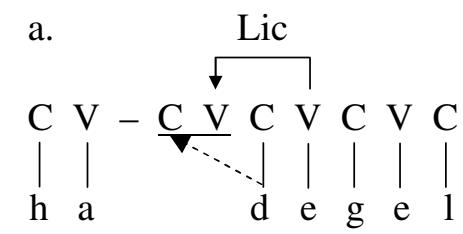

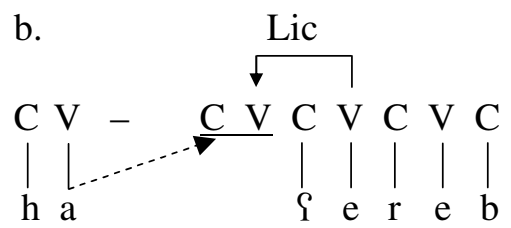

Under the initial CV unit the two attested effects of prefixation in Tiberian Hebrew can rightly be treated as the only two logical outcomes. Such alternations therefore provide independent support for assuming an initial CV unit.

A second important issue that Lowenstamm argues the initial CV unit accounts for is the distribution of initial clusters. So far we have argued

\footnotetext{
${ }^{8}$ Notice that by assuming an initial CV unit in Tiberian Hebrew it must be categorised contrary to surface facts as a language with only sonority-increasing clusters in initial position. However, Tobias Scheer and Delphine Seigneur point out to us that there is compelling evidence that nouns treated as having clusters of the sonority-decreasing type initially actually betray remnants of an intervening schwa-like melody manifested in the spirantisation of following stops. This ongoing debate is beyond the scope of this paper.
} 
that clusters of increasing sonority are represented via an infra-segmental governing relation that renders the intervening vowel inert. What we have said nothing about is how clusters of decreasing sonority are handled. Word-internally the brief discussion of word-internal codas revealed that such clusters are separated by an empty nucleus, as in the English example contain. If we take into account that infra-segmental government is regulated by strict directionality (i.e. head-final), then word-initial clusters of the sonority-decreasing type cannot be licensed via infra-segmental government. In this case, as in the case of the internal /nt/ cluster, we assume that the cluster is derived via proper government, which has the effect of totally inhibiting the segmental expression of its target. Thus in English contain the idea is that the $\mathrm{V}$ position containing /a/ properly governs the preceding empty position to allow it to remain empty. Sonority-decreasing initial clusters will therefore be treated as involving proper government. The question that arises then is that if languages like English are able to license word-internal clusters of decreasing sonority (henceforth referred to as RT clusters) via proper government, why can they not do the same in initial position?

Lowenstamm (1999) and later Scheer (2004) argue that the initial CV unit can be used to explain a cross-linguistically observed implicational relation in the distribution of clusters in initial position - namely, if a language has word-initial RT clusters then it also has initial TR clusters (where the latter refers to sonority-increasing clusters). The reverse, on the other hand, does not hold. So a language may have only TR initial clusters, like English, but not initial RT clusters. The claim is that this follows from the presence versus absence of the initial $\mathrm{CV}$ unit in the two language types; the initial $\mathrm{CV}$ unit is present in TR-only languages but absent in languages with no restrictions on the initial cluster type. ${ }^{9}$ Consider how this follows from the illustrations in (10) and (11), where IG stands for infra-segmental government, PG stands for proper government, and the initial CV unit is underlined.

9 There is some debate surrounding the alternating nature of the initial CV unit. Regarded simply as a boundary marker, we would expect it to be present in all languages. Yet going a step further and suggesting that its presence accounts for differences in syllable structure types implies that it must be parametric. Scheer $(2005,2007)$ argues that it is part of the morpho-syntactic information sent down to the phonology to facilitate the interface between syntax and phonology. Simplifying somewhat, we will assume for the present discussion that it is parametric, available in some languages but not in others. 
(10) TR-only languages (French, English)

a.

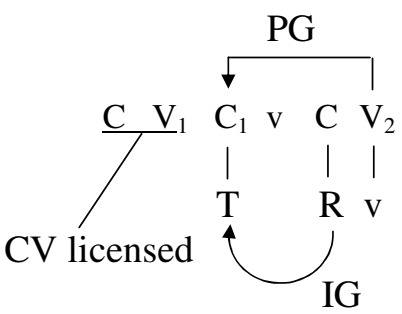

b. $\quad$ PG

$\mathrm{CV}$ unlicensed

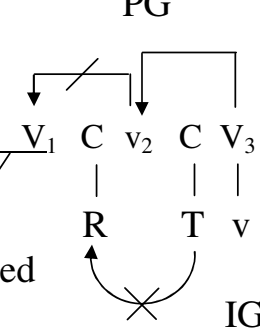

In (10a) we see the initial TR cluster licensed by infra-segmental government that goes from right to left. As we have already discussed, assuming the presence of the initial $\mathrm{CV}$ unit implies that it must be licensed in order to be licit in the structure. This licensing comes via proper government of $V_{1}$ by $V_{2}$. Now if (10a) represents a language with TR clusters then (10b) cannot hold in that same language because the initial CV unit would fail to be licensed in this instance. Given the directionality of infra-segmental government the RT cluster in (10b) cannot be licensed by it and must be licensed by proper government where $V_{3}$ properly governs $V_{2} . V_{2}$ being unrealised is unable to properly govern $V_{1}$ thereby rendering the initial $\mathrm{CV}$ unit unlicensed. $\mathrm{V}_{3}$ cannot directly properly govern $V_{1}$ as this would entail a locality violation since $V_{2}$ though unrealised is an active member of the representation, unlike the inert cluster-sandwiched vowel of (10a). It is therefore not possible for an RT cluster to appear in a licit structure in a language that has the initial CV unit. The presence of an initial CV unit therefore characterises a language as having clusters of increasing sonority in initial position but not ones of decreasing sonority. Let us now consider the case of languages without the initial CV unit representing languages with no restriction on initial cluster type.

(11) Both TR and RT cluster languages (Czech, Moroccan Arabic, Polish)

a.

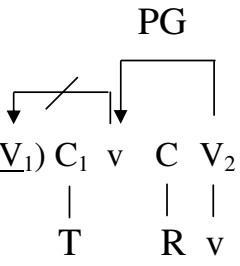

CV licensed

$\mathrm{CV}$ unlicensed

b. $\quad$ PG

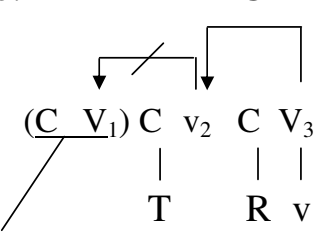


The initial RT cluster in (11a) is licensed via proper government by $\mathrm{V}_{2}$ properly governing $\mathrm{V}_{1}$. In this case, if an initial $\mathrm{CV}$ unit were available it would fail to be licensed. The TR cluster in this language type must also be licensed via proper government because as a language without an initial $\mathrm{CV}$ unit the government potential of $\mathrm{V}_{2}$ would land on both $\mathrm{C}$ positions of the cluster if infra-segmental government, under which $\mathrm{V}_{1}$ would be inert, were assumed. Under this analysis a potentially available initial CV unit would fail to be licensed.

Thus the distributional facts of word-initial clusters follow from the fact that TR-only languages fail to license the initial CV unit whenever they are faced with an RT cluster, while languages entertaining both cluster types, which have no initial CV unit, face no such dilemma. The initial CV unit thus aids the characterisation of these two language types.

The final motivation for the initial $\mathrm{CV}$ unit comes from the characterisation of strong positions, as alluded to above and as discussed in detail in Ségéral and Scheer (2001). As noted in $\$ 2$, strong positions can be regarded as ones which are licensed but not governed. We ended \$2 with the challenge that it was not clear how the initial position could be differentiated from the intervocalic position since both are followed by a realised vowel that both licenses and governs the preceding $\mathrm{C}$ position, in this case making both positions weak. The attentive reader would have already worked out how this is resolved by the presence of the initial CV unit. In (10a), for example, the initial CV unit provides a landing site for the governing potential of $\mathrm{V}_{2}$ which would otherwise have landed on $\mathrm{C}_{1}$. Thus by virtue of having the initial CV unit in (10a), we are able to define languages with initial TR-clusters as having a strong initial position. By the same token we can also represent positions in the 'coda-mirror' in identical fashion. 'Coda-mirror' is a term coined by Ségéral and Scheer (2001) to refer to positions that are a mirror image of the coda position. Ségéral and Scheer argue that these positions are always strong, in contrast to the weak coda. In Strict CV terms the coda is any position that is followed by an empty position, the mirror image of which is any position that is preceded by an empty position. It is for this reason that Ségéral and Scheer argue that post-coda positions and initial positions must be represented in identical fashion, echoing the Coda Licensing Principle of Kaye (1990). The initial CV unit, as shown in (12), facilitates the formalisation of this observation. 
(12) a. Coda positions: weak final coda

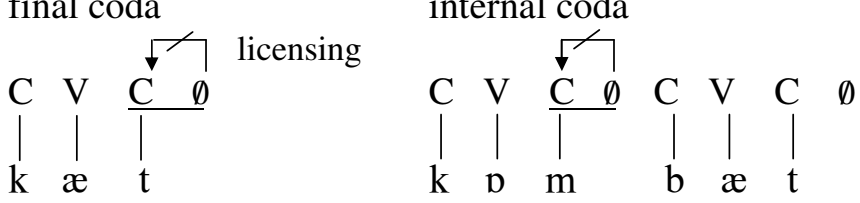

b. Coda-mirror positions: strong initial position

$$
\text { post-coda position }
$$

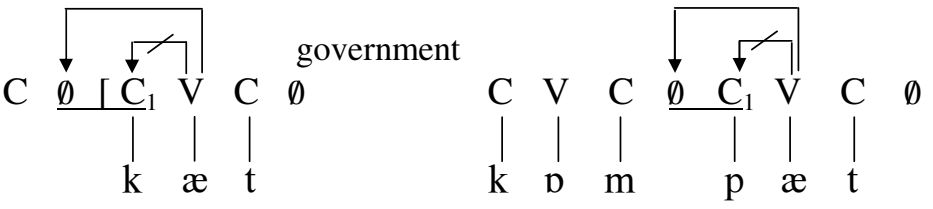

(12a) shows that coda positions that are considered to be weak are represented in an identical fashion whether they are final or internal; the coda is weak in both cases because it lacks a licensor - the unrealised final vowel cannot act as a licensor. (12b) shows that by making reference to the initial $\mathrm{CV}$ unit (represented here as occurring before the square bracket) the initial position and the post-coda position can be represented identically matching their observed strong status. In both cases the strong position $\mathrm{C}_{1}$ is preceded by an empty position that must be licensed via proper government by a following realised vowel which, as such, will not govern $C_{1}$; the latter then emerges as strong since it is licensed but escapes government.

On the other hand, languages without an initial CV unit - i.e. languages allowing initial RT clusters - will have an initial position that has tendencies for weakness because in this case the initial vowel of the word is empty and cannot act as a licensor of the initial $\mathrm{C}$ position. Consider the case of an initial RT cluster in (13).

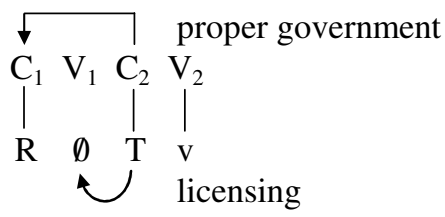

In this case the initial position is weak because it is unlicensed; $V_{1}$ being empty by virtue of being properly governed by $\mathrm{V}_{2}$ cannot act as a licensor of $\mathrm{C}_{1}$. In this same language type the initial position still remains weak 
even in words where $V_{1}$ is realised because, in the absence of an initial CV unit, $\mathrm{V}_{1}$ will both govern and license $\mathrm{C}_{1}$, the opposing forces resulting in at least some weakening effects as discussed in $\$ 2$ and exemplified here in (14).

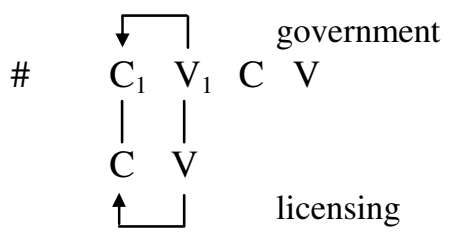

There is empirical evidence supporting weakness in initial position in some North-Eastern Polish dialects discussed in Kijak (2005), where a process of yod strengthening fails to hold in initial position as well as all weak positions in contrast to the post-coda position. Consider the following examples from the Kurp and Mazovian dialects, taken from Kijak (2005).

(15) Generalisation: $\mathrm{j} \rightarrow \mathrm{z} / \mathrm{C}$

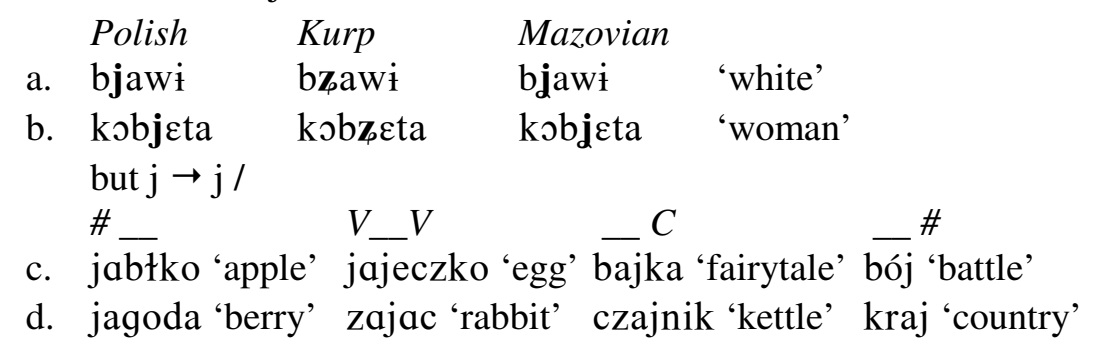

The two dialects of Polish in (15) pattern as expected if they have no initial $\mathrm{CV}$ unit; the initial position is weak, showing no yod strengthening just like in other weak positions in $(15 \mathrm{~cd})$. In contrast to this, the post-coda position in these dialects is strong because it is a position that occurs after an empty $\mathrm{V}$ position but is followed by a filled $\mathrm{V}$ position. In each case in the Polish dialects in (15ab) the post-coda consonant shown in bold escapes the governing power of the following $\mathrm{V}$ position because it must properly govern the $\mathrm{V}$ position between the clusters; the post-coda position is therefore licensed but ungoverned and therefore a strong position. This contrast in the representation of the post-coda position and the initial position is achieved in this case precisely because an initial $\mathrm{CV}$ unit is absent. 
From the foregoing we have seen at least three compelling arguments in favour of an initial CV unit as a part of phonological representation determined on parametric grounds on a language-by-language basis. Firstly, we are able to account for otherwise puzzling clitic alternations as attested in Tiberian Hebrew. Secondly, we can account for the patterning of languages with regard to the distribution of initial clusters where languages of IndoEuropean origin only allow TR clusters while those that are not of IndoEuropean origin allow both TR and RT clusters in initial position. Thirdly, we are able to characterise the initial position as strong in a similar manner to the post-coda position by maintaining that just like the latter position, the initial position is strong because it is not governed.

Kristo and Scheer (2005) summarise these findings under the claim that the presence or absence of the initial $\mathrm{CV}$ unit is concurrent with the following three otherwise seemingly unrelated typological features:

(16) Properties that differentiate the two language types
a. without initial CV
b. with initial CV
i. initial clusters that violate
i. initial clusters do not violate sonority sequencing sonority sequencing
ii. possibility of first vowel of word to alternate with zero
ii. impossibility of first vowel to alternate with zero
iii. initial $\mathrm{C}$ is weak
iii. initial $\mathrm{C}$ is strong

The initial CV unit therefore aids the characterisation of languages according to the types of clusters that they have in initial position, and further, makes predictions on whether the initial position is strong or weak.

With this ample discussion on the characterisation of initial strength in Strict CV we can move on to tackle languages without clusters. How do they fit into the picture and what predictions does the foregoing discussion make with regard to them? The three properties discussed in (16) are only dimly helpful as they are after all aimed at languages without clusters. Property (i) is irrelevant since there are no clusters. Property (ii) would favour (16b) since languages without clusters exhibit no vowel-zero alternations and therefore point to an initial CV unit. Property (iii) can be decided based on empirical evidence. As it stands we are unable to decide (based on these properties) whether the initial position in clusterless languages tolerates an initial CV unit which may further help us decide whether the initial position is strong or weak. 


\section{Casting doubt on the initial CV unit in clusterless languages}

We have argued in the previous section that a language like English possesses an initial CV unit that explains why clusters of decreasing sonority are not possible in this language. We also know, as shown by example (9b), that English allows a $C$ position in initial position to be followed by a realised $\mathrm{V}$ position. In this case as well we want to claim that the initial position is strong and therefore an initial CV unit must precede it. We can easily extend this argument to languages without clusters and make the prediction that if a language lacks clusters and shows strength in initial position then an initial CV unit must be present. If, on the other hand, the initial position has weakening tendencies, then we could claim that the initial CV unit is absent, hence the weakness. This is a position we must entertain for those words in languages with both TR and RT clusters that allow no initial clusters. For the languages with initial clusters, we are able to make a decision as to whether they possess the initial CV unit based on their cluster patterning. In languages without clusters this is obviously not a possibility and it is necessary to find independent grounds on which we can ascertain this. On the face of it, it is quite easy to argue that an initial $\mathrm{CV}$ unit can easily be licensed in a clusterless language that does not allow the initial vowel in a word to alternate with zero because this vowel can always act as a proper governor of the initial CV unit and thereby license it. With the initial CV unit present we can then make the prediction on theoretical grounds that the initial position must be strong because the initial $\mathrm{C}$ position escapes government which targets the vowel of the initial CV unit. Our theory therefore points us in the direction of an initial CV unit, but can we find other evidence to support this in the absence of initial cluster patterning?

One way would be to determine whether prefixation processes, as seen in Tiberian Hebrew, for example, take recourse to an initial CV unit in clusterless languages. Bantu languages, which are rich in affixation and attest an abundance of morphology-phonology interactions, seem a good basis for this investigation. Note though that in treating Bantu languages as clusterless we refer particularly to the fact that they do not have TR or RT clusters (what we may term true clusters) at the beginning of the word or indeed anywhere else in the word apart from NC clusters. In the same vein languages with only geminate clusters will be treated as clusterless. We return to this issue at the end of $\S 4.5$.

Let us consider a few examples that shed light on the status of the initial $\mathrm{CV}$ unit in Bantu. We focus in particular on processes that are not only 
commonplace in Bantu but also fairly widespread; gliding accompanied by compensatory lengthening, vowel and consonant elision and the effects of prefix deletion. ${ }^{10}$ In each of these cases, following fairly basic analyses, we will access whether the presence of an initial CV unit is compatible with the attested outputs.

\subsection{Gliding and compensatory lengthening}

Lumasaaba, a Bantu language of Eastern Uganda (Brown 1972), exhibits compensatory lengthening when gliding results from two vowels coming into contact just in case the initial vowel is high. Gliding and the resultant compensatory lengthening can be seen between a prefix and a stem. In (17) we see this for nominal prefixation where $m u$ - and $m i$ - (here underlined) are prefixed to a vowel-initial stem. The examples here involve two prefixes and a stem, the second prefix providing the relevant environment.
a. u-mu-ana $\rightarrow$ umwa:na 'child'
b. gi-mi-enia $\rightarrow$ gimye:ja 'song'

Vowel hiatus is not allowed in Lumasaaba; when two vowels come in contact they either fuse to create a long vowel or if the first vowel is high as in (17ab) it becomes a glide while the adjacent vowel lengthens. The standard analysis assumes that the high vowel loses its association to a vocalic position and becomes a secondary articulation on the preceding consonant. The position that the high vowel vacates is then filled by the initial vowel of the stem which lengthens as a result. In (18) we give a representation of this analysis in Strict CV showing both the case when an initial CV unit is absent (18a) and when it is present (18b). Recall that the initial CV unit is postulated as occurring before words of major categories and therefore not before prefixes. The initial $\mathrm{CV}$ unit is underlined in $(18 b) .{ }^{11}$

${ }^{10}$ Arguments presented here are drawn from Kula (2006b).

${ }^{11}$ Strict CV assumes as in SGP that segments are composed of elements which are the objects that are manipulated in featural changes. See Harris and Lindsey (1995) on elements. Here we use the elements IA I U LI, which are most closely related to coronality, palatality, labiality and nasality, respectively. 
(18)

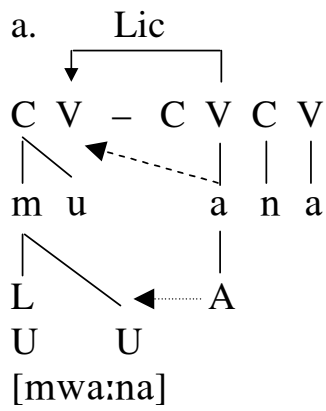

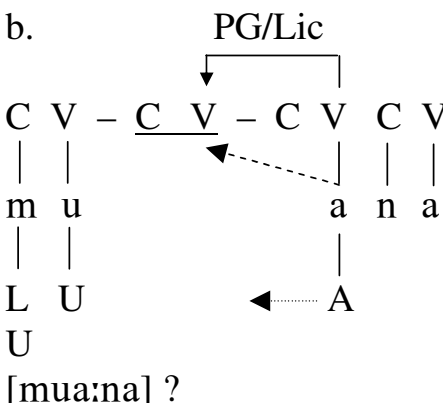

We treat gliding as resulting from restrictions on the combinations of elements that vowels are composed of, particularly, restrictions on spreading. ${ }^{12}$ In (18a) an IAl-element must spread when two vowels are juxtaposed but cannot spread into an expression that contains IUI or III. The mandatory spreading need of the IAI-element forces the IUI-element to shift to the preceding $\mathrm{C}$ position becoming part of the representation of $/ \mathrm{m} /$ where it assumes a dependent position in the elemental representation that can be loosely interpreted as resulting in secondary articulation on the labial nasal, more precisely resulting in a labialised labial nasal. The |A|element now occupying two $\mathrm{V}$ positions is realised as long, resulting in the output [mwa:na] 'child'. Recall that (18a) does not assume an initial CV unit before the stem -ana whereas (18b) does. In this case the IAl-element spreads into the empty position in the initial CV unit, which is licensed in the representation by proper government. In this case, there is no pressure on the IUI-element of the prefix vowel to shift to the representation of $/ \mathrm{m} /$ in the prefix, meaning that we end up with a hiatus situation, the avoidance of which was the initial motivation for the attested phonological processes. Perhaps this representation could be resolved at the phonology-phonetics interface, where the hiatus between a short and long vowel could be phonetically interpreted as a glide followed by a long vowel; but this would fail to relate compensatory lengthening only to those environments where gliding takes place. In fact, under the assumption of an initial CV

12 We assume here the elements IA I U Ll, which get different interpretations depending on whether they appear in a $\mathrm{C}$ or $\mathrm{V}$ position. We also assume complex structures within the elemental representation so that the same element can appear in the same representation if it assumes different positions of either head or dependent as seen with IUI in the representation for what we can consider a labialised labial nasal $/ \mathrm{m}^{\mathrm{w}} /$ in (18a). See Kula (2008) on complex elemental representations but also Botma (2004) on a similar approach. 
unit, we would expect all vowel-initial stems to have a long vowel regardless of what the preceding prefix is - a fact that cannot be substantiated.

Thus though it seems that the representation in (18b) which assumes the initial CV unit could be salvaged by phonetics, the representation in (18a) more straightforwardly accounts for the cause and effect relation seen between gliding and compensatory lengthening.

\subsection{Vowel elision}

A process of vowel elision occurs in a prefix in Lumasaaba whenever the prefix (of CV shape) is followed by a stem that contains a nasal-consonant sequence. As shown in (19), the vowel of the prefix is deleted with the effect of causing the nasal of the NC sequence to become a syllabic nasal. The prefix whose vowel deletes is underlined in (19).

$$
\begin{array}{llll}
\text { a. li-si-anda } & \rightarrow & \text { lisanda } & \text { 'piece of charcoal' } \\
\text { b. ga-ma-anda } & \rightarrow & \text { gamanda } & \text { 'charcoal' }
\end{array}
$$

We will standardly assume that a syllabic nasal is represented as a nasal that is simultaneously in a $\mathrm{C}$ and a $\mathrm{V}$ position. Looking at the representation in (20a), vowel deletion resulting in syllabic nasal formation follows directly from the representation in the absence of the initial CV unit. In this case, the position left vacant by the elided vowel $\left(\mathrm{V}_{1}\right)$ is assumed by the vowel of $V_{2}$, thereby leaving $V_{2}$ vacant. $V_{2}$ cannot remain empty since it is not licensed to remain so - its potential proper governor $V_{3}$ is empty. $V_{2}$ is therefore rescued by the nasal spreading into it, resulting in its syllabic status. If, on the other hand, we assumed an initial CV unit as in (20b), we predict an output where the syllabic nasal is preceded by a long vowel. In this case we must claim that the presence of the initial CV unit causes the initial vowel of the stem in $V_{3}$ to spread into $V_{2}$ and then the newly formed long vowel shifts one place leftwards to fill the gap left by the prefix vowel elision in $V_{1}$. Empty $V_{3}$ then results in the creation of a syllabic nasal. These processes are in themselves not improbable but must be dispelled as they lead us to an incorrect output. The representation in (20a) without the initial CV unit again provides a simpler picture; the loss of one segment is compensated for by another in order to retain the structure of the word. 
(20)

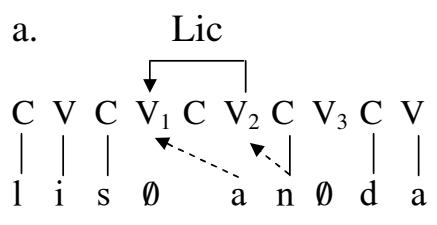

[lisanda]

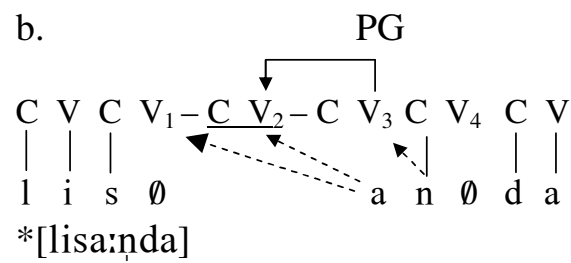

Thus, the absence of an initial CV unit is more strongly supported by the vowel elision facts.

\subsection{Consonant elision}

Alongside vowel elision in prefixes in Lumasaaba is a parallel process of consonant elision in some -VC- shaped prefixes; this results in either vowel lengthening of the prefix vowel (21ab) or, if the stem contains a nasalconsonant sequence, the nasal (like in vowel elision) becoming syllabic, in which case the prefix vowel does not lengthen $(21 \mathrm{~cd})$.

(21) Lumasaaba
a. in-piso
$\rightarrow \quad$ i:pisa
'needle'
b. in-fula
$\rightarrow \quad$ iffula
'rain'
c. in-nepongu $\rightarrow$ inewongu 'bag'
d. in-beba
$\rightarrow \quad$ imbeba
'rat'

As in the vowel elision case, the facts follow directly from the absence of an initial CV unit; the deleted segment of $\mathrm{C}_{2}$ results in vowel lengthening of $V_{1}$ into $V_{2}$ as illustrated in (22a). Contrary to this an initial CV unit would predict gemination of the stem-initial $\mathrm{C}$ in addition to vowel lengthening since, as shown in (22b), the initial CV unit would be licensed in the structure and able to attract adjacent segments to fill it, just like in the Tiberian Hebrew case.

(22)

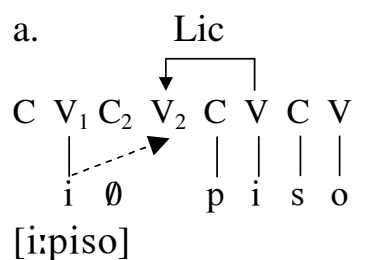

b.

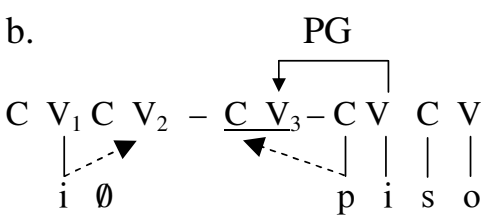

*[i:p:iso] 
Similarly, having an initial CV unit for data such as (21cd) where syllabic nasal formation rather than vowel lengthening takes place, wrongly predicts that under consonant elision both vowel lengthening and syllabic nasal formation will occur since inclusion of an initial CV unit facilitates this in the leftward reshuffling of structure.

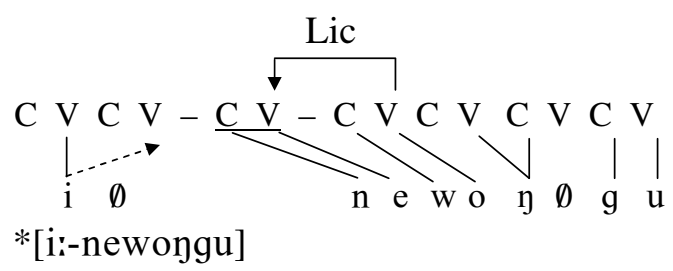

What the facts of Lumasaaba in (21) show is that when a segment is deleted in the prefix, either vowel lengthening or syllabic nasal formation occurs, never both, pointing to fact that there is only one empty position created by consonant deletion and not two as would be the case if an initial $\mathrm{CV}$ unit were assumed.

\subsection{Prefix deletion}

We finally look at a prefix deletion process of Luganda, another Bantu language of Uganda. The process deletes the nominal class 5 prefix $-r i$ resulting in gemination of the stem-initial consonant, as shown in $(24 a-c)$. This gemination can be seen as another case of compensatory lengthening allowable in Luganda where geminates are acceptable. If the stem already begins with a geminate as in (24d) then the prefix is not deleted. The plural forms in the rightmost column show that no gemination occurs with nonalternating prefixes such as the plural prefix ama- ${ }^{13}$
a. e-ri-lagala $\rightarrow$ eddagala 'medicine' ama-lagala(PL.)
b. e-ri-kubo $\rightarrow$ ekkubo 'road/path' ama-kubo (PL.)
c. e-ri-yiinja $\rightarrow$ ejjinja 'stone' ama-yinja (PL.)
d. e-ri-ggwa $\rightarrow$ eriggwa 'thorn' ama-ggwa (PL.) $13 / 1 /$ becomes /d/ and /y/ becomes [ $\left.\mathrm{d}_{3}\right]$ under a standard hardening process in $(24 \mathrm{a})$
and $(24 \mathrm{c})$, respectively. We briefly discuss these fortition processes in $\$ 5.1$. 
The stem-initial $\mathrm{C}$ gemination is straightforwardly accounted for in (25a) by the spreading of the stem-initial $/ \mathrm{k} /$ into $\mathrm{C}_{2}$ which is left vacant by the deleted prefix. Assuming an initial CV unit on the other hand would fail to capture the connection between the gemination process and prefix deletion and further predict gemination even when the prefix is not deleted, as with the plural forms illustrated here in (25b).

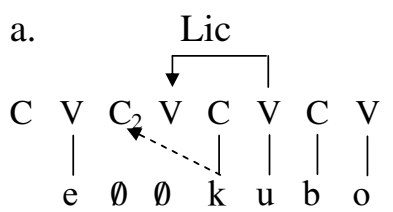

[ekkubo] 'path' b.

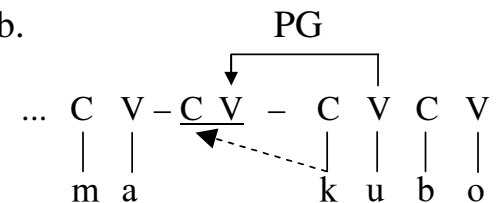

*[amakkubo]

Based on the empirical evidence discussed in the preceding four examples, there seems little motivation for considering the initial CV unit as a part of the representation in Bantu. The question is why should this be and does this extend to all clusterless languages? We will claim yes.

\subsection{Parametric proper government}

As has already been pointed out, the initial $\mathrm{V}$ position of any word in clusterless languages is filled and therefore always available as a potential proper governor and licensor for the initial CV unit. Why does it fail to perform this task? The logical conclusion we must reach is that proper government is simply not active in these languages. This follows from the fact that every vowel must always be realised and processes like vowelzero alternations as attested in languages like Polish and French, for example, do not occur in these languages. Our proposal is thus that proper government is a parametric option that languages may or may not have, and clusterless languages always opt to set this parameter off. In fact, we further postulate that this is the default setting of the parameter and only when it is necessary in a language to define cluster types is the setting changed.

Under this assumption then NC clusters (pseudo-geminates) and geminates are not accounted for by proper government (as also argued in Kula 1999). A crucial difference between these clusters and what we have earlier referred to as true clusters is that they have the requirement to share 
certain features or elements. This implies that true clusters, where there is no such feature sharing (but feature mismatch as seen in infra-segmental government) are not licensed in these languages. We will claim that the $\mathrm{V}$ position sandwiched in geminate and pseudo-geminate clusters is licensed by a C-to-C government relation which requires at least some features to be shared by the two $\mathrm{C}$ positions. Apart from this requirement $\mathrm{C}-$ to- $\mathrm{C}$ government is essentially the same as infra-segmental government in terms of how the intervening $\mathrm{V}$ is licensed and made inert, but differs from it in having no complexity requirement. Consider the representation of this in (26), where C-to-C government defines configurations where all the elements of one $\mathrm{C}$ position are shared with another; the geminate case in (26a), and one where only the place element is shared - the pseudo-geminate cluster in (26b).

(26) a.

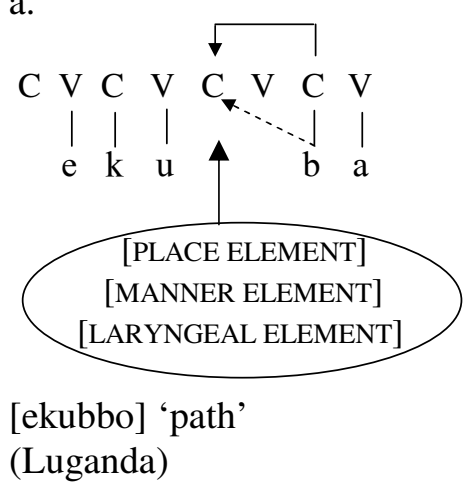

b.

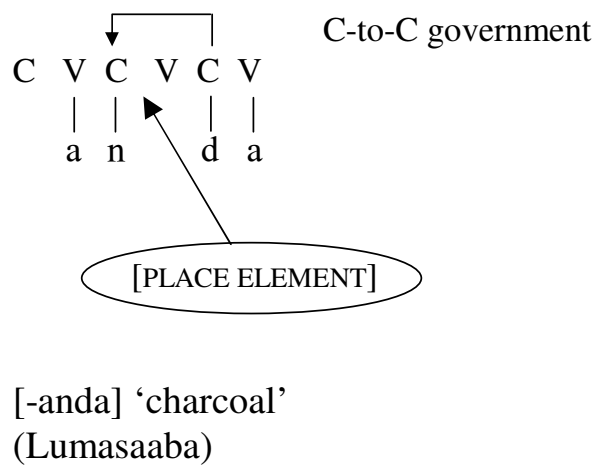

Let us consider in (27) the four logical combinations between proper government and the occurrence of the initial $\mathrm{CV}$ unit and what language type they entail.

(27) Proper government and the initial CV unit

$\begin{array}{ccl}\text { proper gvt. } & \text { initial CV unit } & \text { language type; examples } \\ \checkmark & \checkmark & \text { initial TR only; English, French } \\ \checkmark & \mathbf{x} & \text { TR and RT initially; Czech, Polish } \\ \mathbf{x} & \mathbf{x} & \text { no true clusters; Bantu, Japanese } \\ \mathbf{x} & \checkmark & \text { not an option }{ }^{14}\end{array}$

\footnotetext{
${ }^{14}$ The presence of an initial CV unit without proper government is not an option because the initial $\mathrm{CV}$ unit requires proper government in order to be licensed.
} 
Thus while the presence of proper government in a language tells us nothing about whether an initial CV unit will be available or not, its absence tells us categorically that the initial CV unit is absent as it will never be able to be licensed. (27) may also provide an independent way of assessing the status of proper government in a language; if the presence of true clusters in a language is indicative of the presence of proper government then the absence of true clusters must imply the absence of proper government (see Nasukawa 2005 for a potential counter-example from Japanese).

Having established now that clusterless languages lack an initial CV unit, does this entail that the initial position in these languages will be weak analogous to languages with both RT and TR clusters that lack the initial CV unit? No, because we have established the absence of the initial $\mathrm{CV}$ unit on the grounds of lack of proper government by which we essentially remove the requirement for vowels to govern the $\mathrm{C}$ position that precedes them. In this case we expect the initial position to be strong because it is only licensed but not governed.

In the next section we provide empirical support for considering the initial position as strong in clusterless languages by analysing the distribution of weakening and strengthening processes.

\section{Strength in initial position without the initial $\mathrm{CV}$ unit}

The configuration that emerges from the forgoing discussion is the one in (28) below, where each $\mathrm{C}$ position is licensed by the following $\mathrm{V}$ position but not governed since proper government is inactive. The initial position is strong because it is licensed but ungoverned.

$$
\begin{array}{llll}
\square & \checkmark & \text { licensing } \\
\mathrm{C} & \mathrm{C} & \mathrm{C} & \\
& &
\end{array}
$$

We will consider two pieces of evidence for strength in initial position; a widespread hardening process that affects the initial and the post-coda position in a number of Bantu languages; and a number of weakening processes in Gújjolay Eegimaa (Atlantic) that occur to the exclusion of the initial position. The discussion of Gújjolay Eegimaa will also lead us to a novel proposal for intervocalic weakening. 


\subsection{Fricative and liquid hardening in Bantu}

A number of Bantu languages have a hardening process that changes liquids and fricatives to stops when a nasal prefix precedes them, thereby creating nasal stop clusters. ${ }^{15}$ Since these are the only cluster types attested in word-internal position we can suppose that the process also applies word-internally preferring a strong segment in post-coda position. Consider the data in (29) from Kula (2002: 68). The prefix $n$-marks the $1^{\text {st }}$ person singular.

$\begin{array}{lllll} & \text { verb stem } & \text { N+verb stem } & & \\ \text { a. } & \text { Bila } & \text { mbila } & \text { 'I sew' } & \text { (Bemba) } \\ \text { b. } & \text { leka } & \text { ndeka } & \text { 'I stop' } & \text { (Bemba) } \\ \text { c. } & \text { londa } & \text { o:ndodo } & \text { 'ascend' } & \text { (Kwanyama) } \\ \text { d. } & \text { vevela } & \text { o:mbelela } & \text { 'dip into food' } & \text { (Kwanyama) } \\ \text { e. } & \text { reheete } & \text { ndeheete } & \text { 'I have paid' } & \text { (Kikuyu) } \\ \text { f. } & \text { yoreete } & \text { ngoreete } & \text { 'I have bought' } & \text { (Kikuyu) } \\ \text { g. } & \text { Kora } & \text { mboreete } & \text { 'lop off' } & \text { (Kikuyu) }\end{array}$

Strengthening and hardening, which are treated in the literature as fortition, are here suggestive of strength in initial position. There are also subtle indications that strength occurs towards the left edge of the word in Bantu as the initial position usually attests the greatest number of contrasts, which are considerably reduced in recessive positions.

\subsection{Lenition processes in Gújjolay Eegimaa}

Gújjolay Eegimaa (GE henceforth) is an Atlantic language of Senegal that exhibits a range of weakening processes that will aid our assessment of strength in initial position in this clusterless language. GE exhibits NC clusters and geminates in a consonant system that contrasts bilabial,

15 Also relatively widespread and detrimental to the current analysis is post-nasal voicing which occurs in the same environment. Interestingly, it also occurs in $\mathrm{Ki}$ kuyu which would seem to show conflicting evidence for the initial position. Needless to say, lumping together all Bantu languages under one rubric is probably not a wise thing. We leave a detailed analysis of individual Bantu languages to a future occasion. 
alveolar, palatal and velar plosives and nasals, a small set of fricatives consisting of /f/ and /s/, one lateral /l/ and the two glides /w/ and /y/. The vowel system is relatively more complex contrasting five ATR vowels with five non-ATR ones. All the data to be discussed here are drawn from Sagna (2008).

In the data in (30) we see that the fricative counterparts of /p c k/ only surface in intervocalic and final position, as summarised in (31).
a. pan future particle b. cukkult proper name $\varepsilon \phi a \phi \quad$ 'dust' efan 'canteen'
$\varepsilon$ to $\phi \quad$ 'type of container' $\varepsilon$ y $\int$ 'hat'
c. kakkan 'it is'
Exot 'stick'
Exox 'tie'

(31) $\{\mathrm{p} \mathrm{c} \mathrm{k}\} \rightarrow\left\{\Phi \int \mathrm{x}\right\}$ respectively $/\left\{\begin{array}{c}\mathrm{V}_{-} \mathrm{V} \\ -\# \\ * \#+-\end{array}\right\}$

The voiced counterparts $/ \mathrm{b}$ I g/ also show weakening effects with only the plosives occurring in initial position while their fricative and unreleased counterparts occur in intervocalic and final position respectively, as shown in the data in (32) and summarised in (33).
a. bay 'where'
$\varepsilon \beta a y \quad$ 'put down'
Exob 'crab'
b. garafa 'bottle' eliyis 'summit' Exəg 'be close'
c. Jangu 'church' $\varepsilon j \supset \beta a \quad$ 'dog'
ebaj 'have'
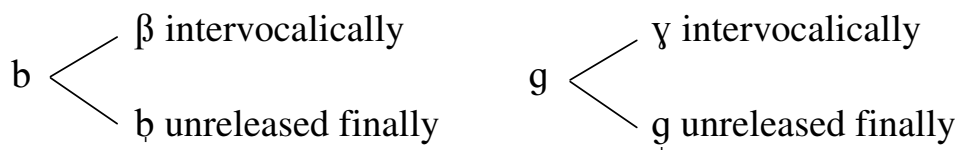


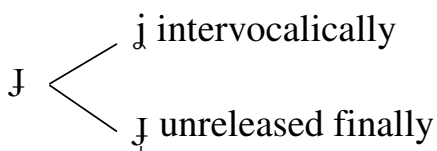

As the data in (30) and (32) show, GE exhibits a distinction between where plosives and their fricative counterparts occur. Plosives only occur in initial position while their weaker forms occur either in final position or in intervocalic position. At least based on these data it is clear to see that the initial position is differentiated as being strong in contrast to the final and intervocalic position. If we contend with earlier findings that GE does not have an initial CV unit because proper government is not active and by virtue of which it lacks true clusters, then we can explain why the initial position is strong - it is a licensed but ungoverned position.

We must also further consider the fact that although the data in (30) make no distinction with regard to the coda and the intervocalic position, (32) does. Our current proposal that proper government is inactive in clusterless languages implies that there is no difference in licensing relations between the initial and intervocalic positions. Recall that intervocalic positions are accounted for as weak in Strict CV by virtue of the fact that they are both governed and licensed. Without government this is no longer possible in clusterless languages; intervocalic position, like initial position, is only licensed.

In order to resolve this problem we will return to an idea put forward in SGP that claims that licensing potential is inherited throughout the domain and not a property that every $\mathrm{V}$ position is endowed with as assumed in Strict CV. Under this guise one V position is the source of all licensing potential that is propagated throughout the whole domain from one $\mathrm{V}$ position to another. In this case a $\mathrm{V}$ position must license the $\mathrm{C}$ position that precedes it but also empower a preceding $\mathrm{V}$ position to license. Consider how this differentiates the intervocalic position from the initial position in clusterless languages.

(34) a.

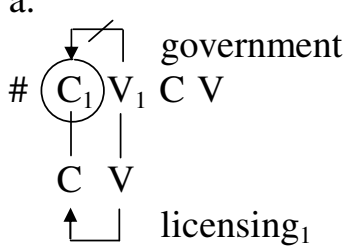

b. $\checkmark \sqrt{\square}$ licensing $_{2}$ $\mathrm{C}_{1} \mathrm{~V}_{1} \mathrm{C}_{2} \mathrm{~V}_{2}$ $\left.\left.\right|_{\mathrm{V}}\right|_{\mathrm{V}}$ ᄂ licensing 1 
(34a) shows the initial position in a clusterless language where proper government is inactive and there is no initial $\mathrm{CV}$ unit. In this case the initial position is licensed by $V_{1}$ and must be strong. The licensing that $C_{1}$ receives in (34a) is to be differentiated from that which $C_{2}$ gets in (34b) in that, while all the licensing potential of $V_{1}$ in (34a) is spent on $C_{1}$, the licensing potential of $V_{2}$ in (34b) must be divided between two targets $C_{2}$ and $V_{1}$ since $V_{2}$ must also additionally license $V_{1}$ with the potential to be able to license $C_{1}$. By this token, every intervocalic position will be licensed to a lesser extent, i.e. with less licensing potential than a nonintervocalic position and will therefore be liable to weakening effects. ${ }^{16}$

Assuming the notion of inherited licensing potential does not change the picture already established for strength relations in languages with true clusters and their recourse or not to the initial CV unit, because proper government is still active in these languages. Inherited licensing potential actually reinforces the generalisations already established for languages with true clusters. Consider the cases below where in each case the source of licensing in $\mathrm{V}_{1}$ is inherited from a recessive $\mathrm{V}$ position. Here, licensing relations are indicated by solid arrows and government by dotted arrows.

a. initial TR only initial CV unit strong initial position

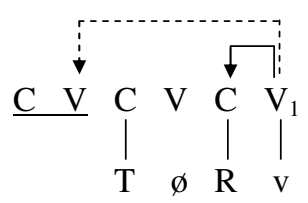

infra-segmental

government b. initial RT and TR clusters

no initial CV unit

weak initial position

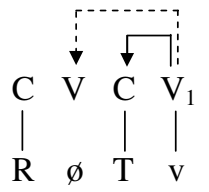

Nothing changes in (35ab) as in each case $\mathrm{C}_{1}$ is the sole target of the licensing potential of $\mathrm{V}_{1}$.

The same holds for a post-coda position that is defined as strong, as this position also receives licensing potential that is not further divided. In effect, inheritance of licensing potential provides further support for the coda-mirror; $\mathrm{C}$ positions that are preceded by an empty position will receive the full licensing potential of their licensing $\mathrm{V}$ position because this

\footnotetext{
16 See Harris (1997) and Kula (2006a) for further discussion on inherited licensing and depletion of licensing potential.
} 
position is not required to license the following $\mathrm{V}$ position because it is empty.

(36) Coda-onset position and licensing potential

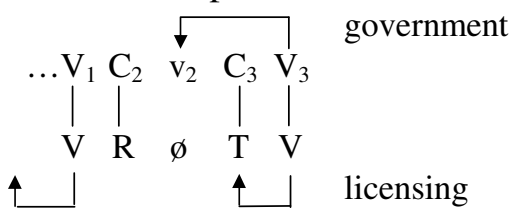

Thus in (36) the licensing potential of $\mathrm{V}_{3}$, itself inherited from a recessive $\mathrm{V}$ position, is fully spent on $\mathrm{C}_{3}$ because $\mathrm{V}_{3}$ does not need to license $\mathrm{V}_{2}-$ an empty position that must be properly governed. We are thus by this token able to differentiate the intervocalic position from the initial position while also still capturing that weakening in this position is to be differentiated from that in a coda position which by contrast lacks licensing.

\section{Enhanced picture of positional strength}

The picture of positional strength that emerges, adapted from Ségéral and Scheer (2001) and Kristo and Scheer (2005), to include clusterless languages is as follows:

(37) Positional strength relations in Strict CV

a. with initial $\mathrm{CV}$ unit: strong initial position (initial TR-only languages)

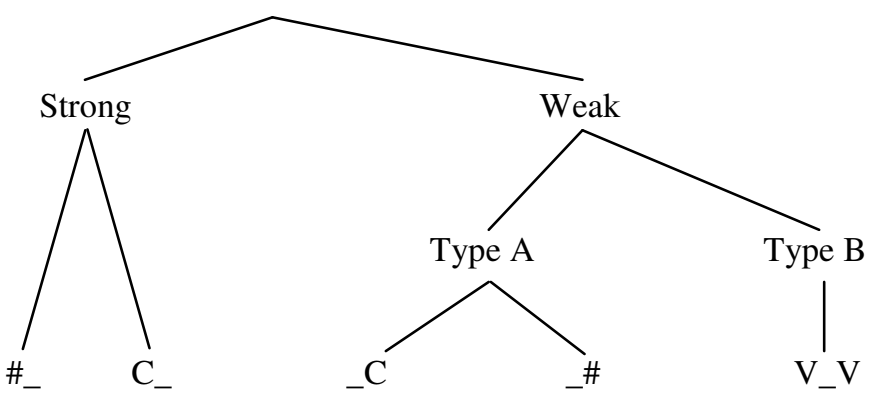

b.

$(\checkmark)$

$(\checkmark)$

(clusterless) 
c. without initial CV unit: weak initial position (initial RT and TR clusters)

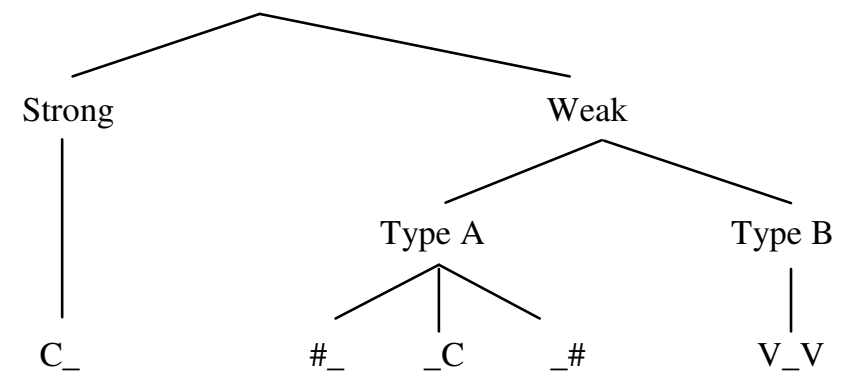

Clusterless languages are sandwiched between the two types of cluster languages showing affinities with both language types in particular respects. By virtue of having a strong initial position they pattern with TR languages in (37a), yet they also pattern with RT languages in not having an initial $\mathrm{CV}$ unit. The post-coda context $\left(\mathrm{C}_{-}\right)$and the coda followed by a $\mathrm{C}$ context (_C) are presented in brackets for the clusterless languages in (37b) because they do not involve true clusters but rather NC clusters. The strength relations posited, however, also hold for these clusters. This distribution seems to favour the idea that it is the possibility or impossibility of alternation of the initial vowel that makes the greatest contribution towards the characterisation of the initial position as strong or weak.

\section{Conclusion}

This paper has shown that the initial CV unit has been used in Strict CV to neatly account for the distribution of cluster types in initial position, with TR languages showing the presence of an initial CV unit and RT clusters showing its absence. Apart from this characterisation into language types it has also been shown that the initial CV unit is used by TR languages as the cushion by which the initial position can successfully evade detrimental government forces and thereby remain strong. Strong positions in Strict $\mathrm{CV}$ are those that are licensed but avoid government. In this sense it seems as though there is a strong correlation between the presence of an initial empty CV unit and a strong initial position in a language. However, we 
have seen strong evidence to suggest that, despite having an initial strong position, the only tenable conclusion for clusterless languages is that they lack an initial CV unit. As per definition of strength in Strict CV it is assumed that the initial position is not governed in clusterless languages and the absence of a proper governor emerges as the most viable explanation that follows from general structural constraints holding in this language type. By parameterising proper government this proposal removes the postulated requirement of Strict CV that nuclei must license and govern. Nuclei must license but government is a parametric option that emerges with the increased complexity of the language, particularly with regard to whether consonant clusters are allowable or not. Under this thinking intervocalic weakening is explained by taking recourse to the idea of inherited licensing potential under the premise that licensing potential diminishes with increased licensing targets. In this way it is possible to differentiate between the weakness of a coda and the weakness of an intervocalic position while retaining the central tenet of Strict CV of lateral relations that adhere to locality.

On the whole then, the presence or absence of an initial CV unit cannot act as a sole factor in determining whether a language has a strong or weak initial position; rather, a language with a strong initial position is one that is able to ensure that the initial position escapes government. In the case of TR languages the initial CV unit provides a good alternative target of governing potential while in clusterless languages the absence of proper government, motivated by the lack of empty positions, ensures that the initial position can never be subject to government and is therefore strong.

\section{Acknowledgements}

We would like to express our thanks to the audience at the workshop Strength Relations in Phonology held at Tohoku Gakuin University in Sendai (September 2006) for discussion of the ideas presented in this paper. Part of this work has also been presented at the annual conference of linguistics in the Netherlands at the University of Utrecht (February 2006). We also thank the reviewers for their insightful comments which have greatly helped the clarity of the argument presented here. We take full responsibility for any errors. 


\section{References}

Botma, Bert 2004

Brown, Gillian 1972

Charette, Monik

1991 Conditions on Phonological Government. Cambridge: Cambridge University Press.

Clements, Nick, and Samuel Keyser

1983 CV Phonology: A Generative Theory of the Syllable. Cambridge, Mass: MIT Press. (Linguistic Inquiry Monographs 9).

Harris, John 1997 Licensing inheritance: an integrated theory of neutralisation. Phonology 14: 315-370.

Harris, John, and Geoff Lindsey

1995 The elements of phonological representation. In Frontiers of Phonology: Atoms, Structures, Derivations, Jacques Durand and Francis Katamba (eds.), 34-79. Harlow, Essex: Longman.

Hulst, Harry G. van der

1995 Radical CV phonology: the categorical gesture. In Frontiers of Phonology: Atoms, Structures, Derivations, Jaques Durand and Francis Katamba (eds.), 80-116. Harlow, Essex: Longman.

Kaye, Jonathan $1990 \quad$ Coda-licensing. Phonology 7: 301-330.

Kaye, Jonathan, Jean Lowenstamm, and Jean-Roger Vergnaud

1985 The internal structure of phonological elements: a theory of charm and government. Phonology Yearbook 2: 305-328.

1990 Constituent structure and government in phonology. Phonology 7: 193-231.

Kijak, Artur 2005

Polish and English complex consonant onsets: a contrastive analysis within the Government Phonology framework. Ph.D. dissertation, University of Silesia.

Kristo, Lazlo, and Tobia Sheer

2005 The beginning of the word in Slavic. Handout available at: www.unice.fr/dsl/tobias.htm. 
Kula, Nancy C.
1999

On the representation of NC clusters in Bemba. In Linguistics in the Netherlands 1999, Renee van Bezooijen and René Kager (eds.), 135-148. Amsterdam: John Benjamins.

2002 The phonology of verbal derivation in Bemba. Ph.D. dissertation, University of Leiden. Published 2002, Utrecht: LOT.

2006a Licensing saturation: co-occurrence restrictions in structure. Linguistic Analysis 32: 366-406.

2006b No initial empty CV in clusterless languages. In Linguistics in the Netherlands 2006, Jeroen van de Weijer and Bettelou Los (eds.), 137-149. Amsterdam: John Benjamins.

2008 Derived environment effects: a representational approach. Lingua 118: $1328-1343$.

Lowenstamm, Jean

$1996 \quad \mathrm{CV}$ as the only syllable type. In Current Trends in Phonology: Models and Methods, Jacques Durand and Bernard Laks (eds.), 419-441. Salford, Manchester: ESRI.

1999 The beginning of the word. In Phonologica 1996, John Rennison and Klaus Kühnhammer (eds.), 153-166. The Hague: Holland Academic Graphics.

Nasukawa, Kuniya

2005 A Unified Approach to Nasality and Voicing. Berlin/New York: Mouton de Gruyter.

Sagna, Serge 2008

Formal and semantic properties of the Gújjolay Eegimaa (a.k.a Banjal) nominal classification system. Ph.D. dissertation, School of Oriental and African Studies, University of London.

Scheer, Tobias

1996 Une théorie de l'interaction directe entre consonnes: contribution au modèle syllabique $\mathrm{CVCV}$, alternances e- $\varnothing$ dans les préfixes tchèques, structure interne des consonnes et la théorie X-barre en phonologie. Ph.D. dissertation, Université Paris 7.

2004 A Lateral Theory of Phonology: What is CV and Why Should It $B e$ ? Berlin/New York: Mouton de Gruyter.

2005 When higher modules talk to phonology they talk to empty nuclei. Paper presented at the Sounds of Silence Workshop, University of Tilburg, October 2005.

2007 On the status of word-initial clusters in Slavic (and elsewhere). In Formal Approaches to Slavic Linguistics, Richard Compton, Magdalena Goledzinowska, and Ulyana Savchenko (eds.), 346364. Ann Arbor, Michigan: Michigan Slavic Publications.

Ségéral, Philippe, and Tobias Scheer

2001 La coda miroir [The coda mirror]. Bulletin de la Société de Linguistique de Paris 96: 107-152. 
Szigetvári, Péter 1999

VC Phonology: a theory of consonantal lenition and phonotactics.

Takahashi, Toyomi Ph.D. dissertation, Eötvös Loránd University, Budapest.

2004

Syllable theory without syllables. Ph.D. dissertation, University College, University of London. 